\title{
Antibiotic susceptibility pattern of Klebsiella pneumoniae and Pseudomonas aeruginosa isolated from some drinking wells in Ondo town southwest Nigeria
}

\author{
${ }^{* 1}$ AROMOLARAN, O; ${ }^{2}$ AMODU, OA \\ *I Microbiology Programme, College of Agriculture, Engineering and Sciences, Bowen University, Iwo, Nigeria \\ ${ }^{2}$ Department of Biological Sciences, Wesley University, Ondo, Nigeria \\ *Corresponding Author Email: kemiaromolaran@gmail.com; Tel: +2348062225745
}

\begin{abstract}
Antibiotic-resistant bacteria (ARB) strains have become a global health threat. This study aimed to determine the antibiotic susceptibility pattern of Klebsiella pneumoniae and Pseudomonas aeruginosa isolated from wells in Ondo town, Southwest Nigeria. Twenty-eight well water samples were analyzed for the presence of $K$. pneumoniae and $P$. aeruginosa by standard pour plate technique. The bacterial isolates were tested against eight commonly use antibiotics using Kirby Bauer disc diffusion method. The percentage occurrence of $K$. pneumoniae and $P$. aeruginosa in the well water samples were $17.86 \%$ and $21.43 \%$, respectively. Two multi-drug resistant strains of $K$. pneumoniae were isolated, which were resistant to at least three classes of antibiotics. Fifty percent of the $P$. aeruginosa isolates were resistant to caftazidime, cefuroxime, nitrofurantoin, and ampicillin. None of the isolates was fully susceptible to cefuroxime, but have all showed resistance to $\beta$-lactam (ceftazidime, cefuroxime augmentin, and ampicillin) antibiotics. Cefuroxime may not be effective an effective drug in the treatment of $K$. pneumoniae and $P$. aeruginosa implicated infections in these communities in Ondo. Also, the over-use of antibiotics should be discouraged in order to curtail the menace of antibiotic resistance.
\end{abstract}

DOI: https://dx.doi.org/10.4314/jasem.v25i1.8

Copyright: Copyright (C) 2021Aromolaran and Amodu. This is an open access article distributed under the Creative Commons Attribution License (CCL), which permits unrestricted use, distribution, and reproduction in any medium, provided the original work is properly cited.

Dates: Received: 02 October 2020; Revised: 26 November 2020; Accepted: 12 December 2020

Keywords: Well water, Antibiotics, Klebsiella pneumoniae, Pseudomonas aeruginosa

Poor access to safe drinking water is a major challenge in many developing countries and this has resulted in waterborne related illnesses and even death in some cases, especially among infants (Novelo et al., 2018; WHO/UNICEF, 2010). In Nigeria, stream water is the main source of water supply in the rural areas, while hand-dug wells supply many communities in the urban centers. Individual owners of residential building in Nigeria construct their septic wells around the building, which are not always far away from the hand-dug wells that supply water to the house. Some of these hand-dug wells are prone to contaminations from septic wells and municipal waste effluents, and these are major repositories for pathogenic microorganisms. Coliforms are members of the family Enterobacteriaceae. Their presence in water could be used as indicator for the presence of some pathogenic microorganisms. The coliform group includes Escherichia coli, Enterobacter aerogenes, and Klebsiella pneumoniae. Although over the years, more attention has been given to antibiotic susceptibility pattern of Escherichia coli in well water, in recent studies, there has been an increase in the incidence of Klebsiella pneumoniae and Pseudomonas aeruginosa in drinking water sources in Nigeria (Ajayi and Agangan, 2011; Aboh et al., 2015; Laniyan et al.,
2016; Bello et al., 2017; Onuoha, 2017). Some strains of Klebsiella pneumoniae isolated from some surface water in Schleswig-Holstein, Germany have been described as equal virulence as clinical strains (Podschun et al., 2001; Kumar and Shrutikirti, 2013). More than eighty percent of Klebsiella pneumoniae isolated from surface water of Tigris River within Baghdad Province were carrying CTX-M genes and were resistant to some antibiotics (Abd Al-kareem et al., 2015). Barati et al. (2016) and Kumar and Shrutikirti (2013) reported the isolation of Klebsiella pneumoniae from environmental samples which could have some public health concerns, such as recurrent urinary tract infection, diarrhea, respiratory tract infection, primary liver abscess, wounds, and soft tissue infections. Pseudomonas aeruginosa is very ubiquitous in the environment and can cause serious infections such as pneumonia, liver abscess, urinary tract infection, and wound infection (Aljanaby, 2008). It has also been implicated in fatal cases of mastitis in humans and animals (Szita et al., 2007). Pseudomonas aeruginosa forms biofilms in clinical and water facilities which are often resistant to many antibiotics (Aljanaby, 2008). Their resistance to antibiotics can be associated with their loss of membrane permeability and ability of efflux pumping of antimicrobial agents 
(Alnour, 2017). Virulent strains of Klebsiella pneumoniae and Pseudomonas aeruginosa have been isolated from the aquatic environments in Malaysia and Iraq, respectively (Aljanaby, 2008; Barati et al., 2016). Antibiotics are usually prescribed in cases of infections and contaminated water has been identified as one of the sources of growth and spread of Pseudomonas aeruginosa and Klebsiella pneumoniae which may colonize humans (Podschun et al., 2001; Szita et al., 2007). Antibiotic resistance is a global health concern and a serious threat in the treatment of infections (Zhang et al., 2006; Roca et al., 2015; Coleman, 2018; WHO, 2020). Many studies have been carried out to determine the presence and antibiotic susceptibility pattern of $E$. coli in wells in Nigeria, but there are only a few reports on Klebsiella pneumoniae and Pseudomonas aeruginosa. In our previous study within communities in Ondo town, we reported high total heterotrophic bacteria and coliform counts. More than $60 \%$ of the wells sampled were positive for $E$. coli, of which $52.78 \%$ were resistant to at least one antibiotic (Aromolaran et al., 2016). Therefore, this study was carried out, as a pilot study to determine the antibiotics susceptibility pattern of Klebsiella pneumoniae and Pseudomonas aeruginosa isolated from wells in Ondo town, Southwest Nigeria.

\section{MATERIALS AND METHODS}

Study site and sample collection: A total of twentyeight (28) water samples were collected from private hand-dug wells in various communities within Ondo town, Southwest Nigeria. The wells selected for this study were used primarily for domestic purposes, such as drinking, cooking, and bathing. The water samples were collected in sterile glass bottles, transported immediately to the laboratory, and analyzed within 6 $\mathrm{h}$ of collection.

Isolation and identification of bacterial isolates from well water: Isolation of bacteria from the water samples was carried out using the pour plate technique. The media used include nutrient agar, triple-sugar-iron agar, phenol-red-carbohydrate broth, and cysteine-lactose-electrolyte deficient (CLED) agar. After $24 \mathrm{~h}$ of incubation, the broth samples were sub-cultured on nutrient agar plates and incubated at $37^{\circ} \mathrm{C}$ for $24 \mathrm{~h}$. Thereafter, discrete colonies were streak on sterile nutrient agar plates to obtain pure culture and biochemical tests were carried out on the isolates. The isolates were identified based on the results of the biochemical tests carried out. Further studies were carried out on isolates identified as Klebsiella pneumoniae, and Pseudomonas aeruginosa.

Antibiotic susceptibility test: The bacteria isolates (K. pneumoniae, and $P$. aeruginosa) were subjected to commonly used antibiotics in Nigeria using Kirby Bauer agar disc diffusion technique as described by Aromolaran and Badejo (2014) and Akinyemi et al. (2005). Pure colonies of bacterial isolates were streaked on sterile Muller Hinton agar (MHA) plates and incubated at $37^{\circ} \mathrm{C}$ for $24 \mathrm{~h}$. The bacterial cells were harvested into sterile normal saline solution and standardized using $0.5 \mathrm{McF}$ arland standards. The cultured cells were introduced on the surface of sterile MHA using sterile swab sticks and multi-disc antibiotics were placed on the culture media aseptically and incubated at $37^{\circ} \mathrm{C}$ for $24 \mathrm{~h}$. The antibiotic discs used were ceftazidime $(30 \mu \mathrm{g})$, cefuroxime $(30 \mu \mathrm{g})$, gentamicin $(10 \mu \mathrm{g})$, ciprofloxacin $(5 \mu \mathrm{g})$, ofloxacin $(5 \mu \mathrm{g})$, nitrofurantoin $(300 \mu \mathrm{g})$, ampicillin $(10 \mu \mathrm{g})$, and augmentin $(30 \mu \mathrm{g})$. The diameter of the zones of inhibition around each disc was measured after the incubation period and recorded.

\section{RESULTS AND DISCUSSION}

Based on the biochemical tests carried out, six $P$. aeruginosa, and five $K$. pneumoniae bacterial strains were isolated and identified from the well water samples within the study area. The percentage occurrence of $K$. pneumoniae and P. aeruginosa in the well samples was $17.86 \%$, and $21.43 \%$, respectively. This is consistent with the report of Bello et al. (2017) who observed an occurrence of $K$. pneumoniae $(9.52 \%)$ and $P$. aeruginosa (23.81) in sachets and bottled water brands sold in Ondo town. Similarly, Venkatesan et al. (2014) also reported a high frequency of occurrence of $K$. pneumoniae (11.9\%) and $P$. aeruginosa (28.6) in packaged drinking water sold in Chennai. Table 1 presents the biochemical characteristics of the isolates. P. aeruginosa were able to ferment glucose with the production of acid, while the Klebsiella species were able to utilize all the sugars tested. The result of this study implied that the bacterial isolates were resistant to some of the antibiotics (Table 2). None of the isolates was sensitive to cefuroxime, while four $K$. pneumoniae and three $P$. aeruginosa showed intermediate resistance. Table 3 showed the antibiotic-resistant pattern of the isolates to some commonly used antibiotics. All the isolates showed resistance to at least $\beta$-lactam class of antibiotics except one of the $P$. aeruginosa. Figure 1 represents the percentage resistance of $K$. pneumoniae and $P$. aeruginosa to the tested antibiotics. None of the $P$. aeruginosa isolated from the well water samples showed full resistance to ofloxacin and augmentin. At least one Klebsiella species was resistant to one of the antibiotics. None of the isolates was fully susceptible to cefuroxime, but have all showed resistance to $\beta$ lactam (ceftazidime, cefuroxime augmentin, and ampicillin) antibiotics (Table 4). Poonia et al. (2014) 
reported that $57.5 \%$ of the bacteria isolated from natural water in rural communities of East Sikkim were resistant to ampicillin, which is similar to this study. About $60 \%$ of the Klebsiella species isolated in this study were resistant to gentamicin and ampicillin. Klebsiella pneumoniae is commonly implicated in reoccurring urinary tract infection (Kumar and
Shrutikirti, 2013; Barati et al., 2016). Twenty percent of the $K$. pneumoniae isolated from the well water were resistant to ciprofloxacin, which is the most common antibiotic used in the treatment of UTI in Ondo town. The resistance could be due to the uncontrolled use of antibiotics, aiding the development of resistance by the bacteria.

Table 1: Biochemical characteristics of P. aeruginosa and K. pneumoniae isolated from well water samples

\begin{tabular}{clll}
\hline S/N & Biochemical tests & P. aeruginosa & K. pneumoniae \\
\hline 1 & Grams reaction & - & - \\
2 & Catalase & + & + \\
3 & H 2 production & - & - \\
4 & Urease & - & + \\
5 & Oxidase & + & - \\
6 & Sucrose & - & AG \\
7 & Lactose & - & $\mathrm{AG}$ \\
8 & Glucose & $\mathrm{AG}$ & $\mathrm{AG}$ \\
9 & Mannitol & - & $\mathrm{AG}$ \\
10 & Sorbitol & - & $\mathrm{AG}$ \\
11 & Mannose & - & $\mathrm{AG}$ \\
12 & Inositol & - & $\mathrm{AG}$ \\
13 & Maltose & - & $\mathrm{AG}$ \\
Keys: + positive; - negative; A - Production of acid; G - Formation of gas
\end{tabular}

Table 2: Antibiotic susceptibility of $P$. aeruginosa and $K$. pneumoniae isolated from well water samples

\begin{tabular}{|c|c|c|c|c|c|c|c|c|c|}
\hline \multirow[b]{2}{*}{ Location code } & \multirow[b]{2}{*}{ Isolates } & \multicolumn{8}{|c|}{ Zone of inhibition in millimeters } \\
\hline & & CAZ & CRX & GEN & CPR & OFL & AUG & NIT & AMP \\
\hline OD2 & Klebsiella pneumoniae & $13(\mathrm{R})$ & 15(I) & 13(I) & $21(\mathrm{~S})$ & $28(\mathrm{~S})$ & $11(\mathrm{R})$ & $19(\mathrm{~S})$ & $17(\mathrm{~S})$ \\
\hline OD4 & Pseudomonas aeruginosa & $15(\mathrm{I})$ & $0(\mathrm{R})$ & 12(R) & $21(\mathrm{~S})$ & $30(\mathrm{~S})$ & $28(\mathrm{~S})$ & $25(\mathrm{~S})$ & $0(\mathrm{R})$ \\
\hline OD5 & Klebsiella pneumoniae & 17(I) & $18(\mathrm{I})$ & $21(\mathrm{~S})$ & $23(\mathrm{~S})$ & $12(\mathrm{R})$ & $14(\mathrm{I})$ & $18(\mathrm{~S})$ & $15(\mathrm{I})$ \\
\hline OD7 & Klebsiella pneumoniae & $18(\mathrm{~S})$ & $14(\mathrm{R})$ & $0(\mathrm{R})$ & $21(\mathrm{~S})$ & $15(\mathrm{I})$ & 14(I) & $14(\mathrm{R})$ & $0(\mathrm{R})$ \\
\hline OD8 & Pseudomonas aeruginosa & 14(R) & $0(\mathrm{R})$ & $19(\mathrm{~S})$ & $18(\mathrm{I})$ & 15(I) & $21(\mathrm{~S})$ & $0(\mathrm{R})$ & $17(\mathrm{~S})$ \\
\hline OD12 & Klebsiella pneumoniae & $19(\mathrm{~S})$ & $15(\mathrm{I})$ & $0(\mathrm{R})$ & $17(\mathrm{I})$ & $19(\mathrm{~S})$ & $21(\mathrm{~S})$ & $19(\mathrm{~S})$ & $0(\mathrm{R})$ \\
\hline OD13 & Pseudomonas aeruginosa & 17(I) & $12(\mathrm{R})$ & $16(\mathrm{~S})$ & $15(\mathrm{R})$ & $21(\mathrm{~S})$ & $17(\mathrm{I})$ & $15(\mathrm{I})$ & $0(\mathrm{R})$ \\
\hline OD15 & Pseudomonas aeruginosa & $17(\mathrm{I})$ & $18(\mathrm{I})$ & $15(\mathrm{~S})$ & $14(\mathrm{R})$ & $19(\mathrm{~S})$ & $16(\mathrm{I})$ & $0(\mathrm{R})$ & $15(\mathrm{I})$ \\
\hline OD17 & Pseudomonas aeruginosa & 14(R) & 17(I) & $15(\mathrm{~S})$ & 19(I) & 13(I) & $15(\mathrm{I})$ & $0(\mathrm{R})$ & $0(\mathrm{R})$ \\
\hline OD23 & Klebsiella pneumoniae & $17(\mathrm{I})$ & $18(\mathrm{I})$ & $0(\mathrm{R})$ & $0(\mathrm{R})$ & $15(\mathrm{I})$ & $17(\mathrm{I})$ & $19(\mathrm{~S})$ & $0(\mathrm{R})$ \\
\hline OD28 & Pseudomonas aeruginosa & $14(\mathrm{R})$ & 19(I) & $21(\mathrm{~S})$ & $18(\mathrm{I})$ & $15(\mathrm{I})$ & $19(\mathrm{~S})$ & $18(\mathrm{~S})$ & $17(\mathrm{~S})$ \\
\hline
\end{tabular}

Table 3: Antibiotic resistant pattern of Klebsiella pneumoniae and Pseudomonas aeruginosa isolated from well water samples

\begin{tabular}{ll}
\hline Bacteria isolates & Resistant pattern (class of antibiotics) \\
\hline K. pneumoniae & OFL ( $\beta$-lactam) \\
& GEN, AMP (aminoglycosides, $\beta$-lactam) \\
& CAZ, AUG ( $\beta$-lactam) \\
& GEN, CPR, AMP (aminoglycosides, fluoroquinolones, $\beta$-lactam) \\
& CRX, GEN, NIT, AMP ( $\beta$-lactam, aminoglycosides, nitrofurantoin) \\
& CAZ ( $\beta$-lactam) \\
& CPR, NIT (fluoroquinolones, nitrofurantoin) \\
& CAZ, NIT, AMP ( $\beta$-lactam nitrofurantoin) \\
& CRX, CPR, AMP ( $\beta$-lactam, fluoroquinolones) \\
& CRX, GEN, AMP ( $\beta$-lactam, aminoglycosides) \\
& CAZ, CRX, NIT ( $\beta$-lactam, nitrofurantoin) \\
\hline
\end{tabular}

Keys: CAZ - Ceftazidime, CRX-Cefuroxime, GEN-Gentamicin, CPR-Ciprofloxacin, OFL-Ofloxacin, AUG; - Augumentin, NITNitrofurantoin, AMP-Ampicillin

Fifty percent of the Pseudomonas species were resistant to ceftazidime, cefuroxime, nitrofurantoin, and ampicillin. Ampicillin and penicillin have been used in the treatment of wound infection for a very long time. The development of resistance to ampicillin by $P$. aeruginosa could also be attributed to extensive use (Lambert, 2002).
The overall antibiotic susceptibility and resistance profile of the bacteria isolates ( $K$. pneumoniae, and $P$. aeruginosa) is presented in Table 4 . None of the isolates was fully susceptible to cefuroxime. However, the isolates showed $54.5 \%$ sensitivity to nitrofurantoin, but $54.5 \%$ resistance to gentamicin and ofloxacin. 


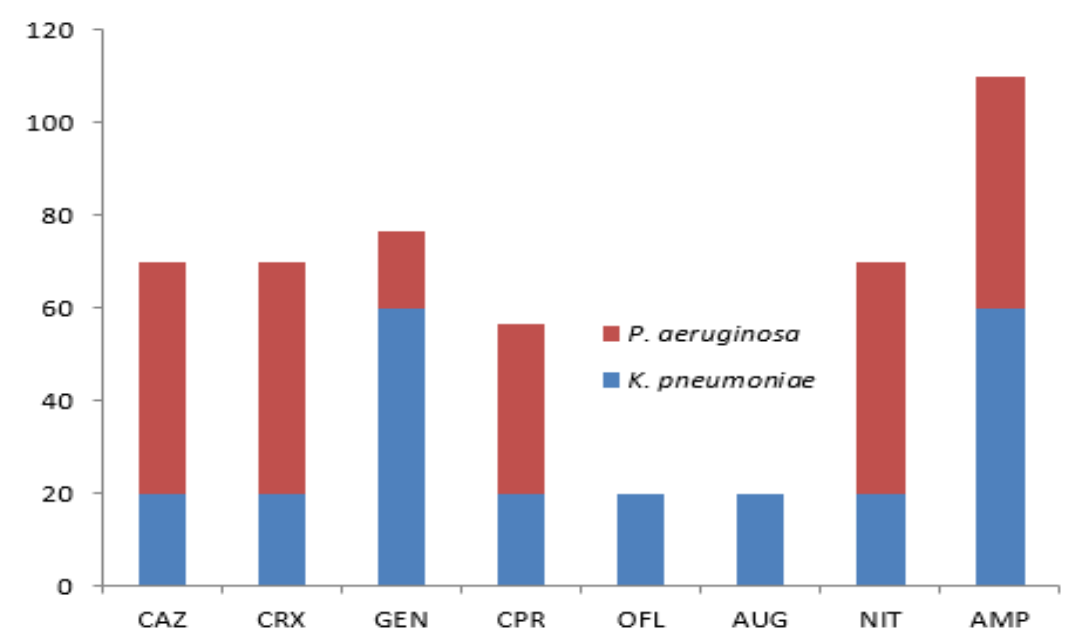

Fig 1: Percentage resistance of Klebsiella pneumoniae and Pseudomonas aeruginosa to antibiotics

Table 4: Antibiotic susceptibility and resistant profile of $K$. pneumoniae and $P$. aeruginosa isolated from well water samples $(\mathrm{N}=11)$

\begin{tabular}{lll}
\hline Antibiotics & Resistant isolates & Susceptible isolates \\
\hline Nitrofurantoin & $5(45.5 \%)$ & $6(54.5 \%)$ \\
Ampicillin & $8(72.7 \%)$ & $3(27.3 \%)$ \\
Ceftazidime & $9(81.8 \%)$ & $2(19.2 \%)$ \\
Cefuroxime & $11(100 \%)$ & $0(0 \%)$ \\
Gentamicin & $6(54.5 \%)$ & $5(45.5 \%)$ \\
Ciprofloxacin & $7(63.6 \%)$ & $4(36.4 \%)$ \\
Ofloxacin & $6(54.5 \%)$ & $5(45.5 \%)$ \\
Augmentin & $7(63.6 \%)$ & $4(36.4 \%)$ \\
\hline \multicolumn{2}{l}{}
\end{tabular}

The percentage occurrence of $K$. pneumoniae, $P$. aeruginosa in the well water samples was $17.86 \%$, and $21.43 \%$, respectively. None of the isolate was fully susceptible to cefuroxime, but have all showed resistance to $\beta$-lactam (ceftazidime, cefuroxime augmentin, and ampicillin) antibiotics. It can be inferred from this study that cefuroxime may not be effective in the treatment of $K$. pneumoniae and $P$. aeruginosa implicated infections in the study area. Also, the release of antibiotic wastewater into the environment and the use of over-the-counter service without the appropriate prescription should be discouraged in our urban centers, so as to reduce the menace of drug resistance.

\section{REFERENCES}

Abd Al-kareem, AF; Al-Arajy, K; Jassim, KA (2015). Prevalence of CTX-M Gene in Klebsiella pneumoniae isolated from surface water of Tigris River within Baghdad Province. Advances in Life Science and Technology 30: 15-19

Aboh, EA; Giwa, FJ; Giwa, A (2015). Microbiological assessment of well water in Samaru, Zaria, Kaduna State, Nigeria. Annals of African Medicine 14(1): 32-38.
Ajayi, AO; Agangan, NF (2011). Antibiotic susceptibility testing of bacteria in drinking water sources in Akungba-Akoko, Ondo State, Nigeria. South Asian Journal of Experimental Biology 1(4): 233-237.

Akinyemi, KO; Oladapo, O; Okwara, CE; Ibe, CC; Fasure, KA (2005). Screening of crude extract of six medicinal plants used in Southwest Nigeria unorthodox medicine for anti-methicillin resistant Staphylococcus aureus activity. BMC Complement Alternative Medicine 5: 6.

Aljanaby, AAJ (2008). Antibiotic susceptibility pattern and virulence associated genes in clinical and environmental strains of Pseudomonas aeruginosa in Iraq. Asian Journal of Scientific Research 11:401-408.

Alnour, TMS; Ahmed-Abakur, EH (2017). Multi-drug resistant Pseudomonas aeruginosa: Medical impact, pathogenicity, resistant mechanism and epidemiology. JSM Microbiology 5(3): 1046-1054.

Aromolaran, O; Adesola-Famade, O; Omoseyin, OE (2016). Incidence of antibiotic resistant E. coli isolated from drinking water sources in Ondo, 
southwestern Nigeria. British Microbiology Research J 16(1): 1-7.

Aromolaran, O; Badejo, OK (2014). Efficacy of fresh leaf extract of Spondias mombin against some clinical bacterial isolate from typhoid patients. Asian Journal of Tropical Disease 4(6): 442-446.

Barati, A; Ghaderpour, A; Chew, LL; Bong, CW; Thong, KL; Chong, VC; Chai, LC (2016). Isolation and characterization of aquatic borne Klebsiella pneumoniae from tropical estuaries in Malaysia. International Journal of Environmental Research and Public Health 13: 426-442.

Bello, OO; Oni, MO; Bello, TK; Amoo, OT (2017). Occurrence of antibiotic resistant bacteria in sachet and bottled water brands in Ondo City, Nigeria. International Journal of Advanced Research and Publications 1(6): 58-68.

Coleman, BL (2018). The role of drinking water as a source of transmission of antimicrobial resistant $E$. coli. PhD Thesis, University of Toronto.

Kumar, D; Shrutikirti, KK (2013). Klebsiella in drinking water. International Journal of Pharmaceutical Science Invention 2(12): 38-42.

Lambert, PA (2002). Mechanism of antibiotic resistance in Pseudomonas aeruginosa. Journal of the Royal Society of Medicine 95 (41): 22-26.

Laniyan, TA; Olatunji, AS; Bayewu, OO; Mosuro, GO; Odukoya, MO; Kenjinu, S; Odunuga, ST (2016). Physicochemical assessment and bacteriological studies of hand-dug wells of major markets in southwest Nigeria. Arabian Journal of Geoscience 9: 261-269.

Novelo, JAM; Revollo-Fernandez, DA; Tapia, LR (2018). Inequality in access to drinking water and subsidies between low and high income households in Mexico City. Water 10(8): 1-16.
Onuoha, SC (2017). The prevalence of antibiotic resistant diarrhogenic bacterial species in surface water, Southeast Nigeria. Journal of Health Sciences 27(4): 319-330.

Podschun, R; Pietsch, S; Holler, C; Ullmann, U (2001). Incidence of Klebsiella species in surface water and their expression of virulence factors. Applied Environmental Microbiology 67(7): 33253327.

Poonia, S; Singh, TS; Tsering, DC (2014). Antibiotic susceptibility profile of bacteria isolated from natural sources of water rural areas of East Sikkim. Indian Journal of Community Medicine 39(3): 156160.

Roca, I; Akova, M; Baquero, F; Carlet, J; Cavaleri, M; Coenen, $S$ et al (2015). The global threat of antimicrobial resistance: science for intervention. New Microbes New Infection 6:22-29.

Szita, G; Gyenes, M; Soos, L; Retfalvi, T; Bekesi, L; Csiko, G; Betnath, S (2007). Detection of Pseudomonas aeruginosa in water samples using a novel synthetic medium and impedimetric technology. Letters in Applied Microbiology 45: $42-46$.

Venkatesan, KD; Balaji, M; Victor, K (2014). Microbiological analysis of packaged drinking water sold in Chennai. International Journal of Medical Science and Public Health 3(4): 472-476.

WHO/UNICEF (2010). Joint Monitoring Program for water supply and sanitation. Progress on sanitation and drinking water WHO Geneva.

World Health Organization (2020). Antimicrobial resistance. Available: https://www.who.int Date accessed 30/10/2020.

Zhang, R; Eggleston, K; Rotimi, V; Zeckhauser, RJ (2006). Antibiotic resistance as a global threat: evidence from China, Kuwait and the United States. Globalization and Health 2(6): doi.org/10.1186/1744-8603-2-6. 